\title{
ALFABETIZACIÓN DIGITAL Y DOCENCIA UNIVERSITARIA: EL CASO DE LA ESCUELA DE PERIODISMO DE LA USACH
}

\section{Introducción}

En las últimas décadas, los programas de alfabetización digital se han convertido en una prioridad gubernamental a través de la cual se pretende, por una parte, contribuir al desarrollo integral del país y, por otra, disminuir las brechas socioeconómicas de su población. Para ello, las autoridades han desplegado dispositivos tecnológicos a gran escala que se complementan con abundantes accesos públicos a internet y planes de formación masiva y diferenciada.

Los procesos de "alfabetización", sin embargo, están enfrentando una situación compleja que, más allá de la eficiente instalación y uso de herramientas informáticas, disminuye notablemente su difusión efectiva. Se trata de las diferencias de lectura cultural que experimentan sujetos de distintas generaciones para asumir las nuevas tecnologías y, con ellas, medios de comunicación que codifican de manera cada vez más compleja y diversa. En este contexto, la actividad docente, particularmente la universitaria, se desarrolla entre sujetos que navegan en paralelo y en distintos soportes comunicacionales, con diversidad de códigos y disímil capacidad de "traducción" de un sistema a otro. ¿Cuánto se han adaptado los profesores universitarios a estas nuevas tecnologías? ¿De qué manera se interrelacionan generaciones de distinta "cultura" tecnológica? ¿Hasta qué punto los cambios tecnológicos y comunicacionales están afectando las metodologías pedagógicas?

El Informe sobre Desarrollo Humano en Chile 2006 "Las tecnologías: un salto al futuro", del Programa de las Naciones Unidas para el Desarrollo (PNUD), señala que el uso masivo en Chile del celular, la televisión, la computación e internet no producirán un 
salto cualitativo hacia el desarrollo humano si, al mismo tiempo, no se crean las condiciones que permitan ponerlas al servicio de la sociedad y las personas.

Un análisis de las transformaciones en la educación, el trabajo y la participación ciudadana da cuenta de que en estos tres ámbitos las expectativas sobre la contribución de la tecnología no se han cumplido. Estas generan oportunidades para el país sólo si están al servicio de la sociedad y las personas.

El Informe concluye que no basta con adquirir más y mejores tecnologías, ni con reconvertir los procesos productivos, políticos y sociales. El desafío es apropiarse de ellas y saber usarlas. Para aprovechar sus potencialidades y neutralizar sus amenazas, el PNUD plantea la necesidad de disponer de condiciones socioculturales favorables, que no se desprenden de la expansión de las tecnologías mismas, sino que deben ser creadas intencionalmente por la sociedad en su conjunto.

Precisamente, este estudio se refiere al uso de nuevas tecnologías en el aula, en un ámbito muy acotado, como lo es la Escuela de Periodismo de la Universidad de Santiago de Chile, lo cual tiene la particularidad de poner en juego la problemática de la alfabetización digital en un contexto especializado, ya que los fenómenos comunicacionales son, precisamente, objetos de estudio de una unidad académica como ésta.

\section{Marco conceptual}

Son muchas las ventajas que los sistemas sociales encuentran en las nuevas tecnologías, como la optimización del tiempo de las personas en distintas actividades productivas y de otra índole, aspectos de convivencia y participación: "Movimientos de democratización desde abajo encuentran en las tecnologías - de producción como la cámara portátil, de recepción como las parabólicas, de postproducción como el computador y de difusión como el cable- la posibilidad de multiplicar las imágenes de nuestra sociedad desde lo regional a lo municipal e incluso lo barrial" (Martín-Barbero, 2006). Sin embargo, también 
estos cambios generan nuevos problemas pues, pese a la rapidez con que se introducen las tecnologías de información y comunicación (TIC) en el mundo, el nivel de acceso y beneficio "varía mucho entre países, regiones, sectores, industrias y empresas. Los beneficios, en forma de prosperidad, y los costes, en forma de precio del cambio, tienen una distribución desigual entre diferentes países de la Unión y entre ciudadanos" (Trejo Delarbre, 2001).

En este contexto, Castells señala que el desafío consiste en eliminar las trabas que generan la desigualdad, para así concebir que conceptos como la "Sociedad de la Información" se extiendan en sus procesos de inclusión. Es importante señalar que "las nuevas tecnologías de la información no son sólo herramientas que aplicar, sino procesos que desarrollar" (Castells, 1996: 58). El autor explica que "aún no está claro cuánta sociabilidad está habiendo en esas redes electrónicas y cuáles son los efectos electrónicos de una forma de sociabilidad nueva. No obstante, cabe destacar un rasgo: estas redes son efímeras en lo que respecta a los participantes (...) la mayoría de las contribuciones a la interacción son esporádicas, ya que la mayor parte de la gente entra y sale de las redes según cambian sus intereses o siguen sin cumplirse sus expectativas" (Castells, 1996: 395).

Otro aspecto importante que señala Castells es que la red es sólo un complemento de la actual estructura comunicacional, sugiriendo que no debe estudiarse aisladamente. "El modo de comunicación electrónica de muchos con muchos que representa la comunicación a través del ordenador se ha utilizado de maneras diferentes y con fines distintos, tantos como la gama de variación social y contextual que existe entre sus usuarios. Lo que es común es que, según los escasos estudios sobre el tema, no sustituye a los otros medios de comunicación, ni crea nuevas redes: refuerza a los modelos sociales ya existentes" (Castells, 1996: 58).

Las nuevas tecnologías afectan de manera notable a la actividad cognitiva, pues se produce "una nueva forma de conocimiento que no tendría como soporte la memoria, o la capacidad conceptual, pero que tendría que ver más que con el tipo asociativa que con el abstracto racional" (Diviani, 1998: 96). 
Por ello, las aspiraciones de desarrollar en la red amplios espacios democráticos necesitan de voluntades que atañen tanto a los creadores de los sitios digitales como a la misma ciudadanía y a las autoridades. "No sólo estamos obligados a seguir aprendiendo: las tecnologías de la información y los medios de comunicación también han de adaptarse a esta realidad. Es en este sentido que estimamos esencial considerar el fenómeno de la comunicación desde el punto de vista de la cognición" (Colle, 2002: 18-19).

Precisamente, son los aspectos cognitivos los que hoy aparecen como más afectados por los cambios tecnológicos, pues, casi en directa proporción con la edad, el nivel de turbulencias tecnológicas se ha convertido en el ambiente cotidiano de los usuarios de nuevos medios de comunicación.

Desde los textos alfabéticos, cuyo soporte es el papel, hasta las comunidades virtuales, establecidas en ninguna parte, hemos sido testigos de un grosero desplazamiento en los procedimientos culturales de lectura. Los sujetos están desarrollando nuevas competencias, pues la lectura que hacen de los productos mediáticos ya no se basa únicamente en la linealidad del texto, sino en la construcción de significados a partir de caudales de imágenes, sonidos y "textos" no secuenciales. Estos últimos tienen lecturas diferenciadas y se requieren herramientas para decodificar y significar, de acuerdo con las características particulares de los productos comunicacionales.

La textualidad impresa establece ciertas normas en el lector, pues se trata de un soporte que propicia la secuencia fija, un comienzo y fin de la trama, al modo aristotélico. El contenido se encuentra repartido linealmente, párrafo tras párrafo y página tras página, pues "el lector se sitúa en actitud pasiva, se encuentra atrapado en las dimensiones físicas del libro" (Gómez; Martínez).

Por el contrario, la "textualidad" digital nos enfrenta a una lectura compleja, cuya trayectoria tampoco es casual. El usuario de esta tecnología lleva a cabo el recorrido del texto motivado por la acción voluntaria que encierra el arte de navegar. 
El sujeto familiarizado con las construcciones comunicacionales en internet es un "lector entendido" (Meneses). Determina, a través de su propio mapa conceptual, las infinitas posibilidades de lectura del texto, "soslayando las limitaciones impuestas por los sistemas tradicionales de lectura y escritura, basados en nociones como centro, margen, jerarquía y linealidad" (Calle).

\section{Alfabetización digital}

La importancia de apropiarse de estos códigos y estructuras comunicacionales asociadas al fenómeno digital fue recogida por las políticas del Gobierno de Chile en materia de comunicación a partir de agosto de 2002, a través de la iniciativa denominada Campaña Nacional de Alfabetización Digital, que se realizó hasta 2005. De acuerdo con el Manual del Relator en el Curso de Alfabetización Digital para Pequeños y Microempresarios (SENCE), "se requiere desarrollar un conjunto de políticas y acciones orientadas a situar a nuestro país en la corriente de los desafíos que impone la globalización".

Las acciones de alfabetización digital se llevaron a efecto en más de dos mil puntos a través de todo Chile para los mayores de 15 años. Lugares claves, como establecimientos educacionales del programa del Ministerio de Educación "Enlaces", que se han abierto a la comunidad, las bibliotecas digitales, los infocentros y los centros de capacitación, en los cuales la ciudadanía puede inscribirse para participar, fueron algunos de los espacios que sirvieron a la implementación del programa: "Enlaces, Dirección de Bibliotecas, Archivos y Museos (Dibam), Servicio de Capacitación y Empleo (Sence), Servicio de Cooperación Técnica (Sercotec) y Fondo de Solidaridad e Inversión Social (Fosis), entre otros servicios públicos, han puesto en marcha proyectos de alfabetización digital. El material básico de capacitación es un curso de 18 horas al término del cual los participantes podrán buscar información relevante en internet, comunicarse por correo electrónico, producir y registrar información apoyándose en procesador de texto y planilla de cálculo, y realizar transacciones electrónicas. Los cursos, que se impartieron por una red de más de 2.000 monitores, culminaron con aplicaciones prácticas pertinentes a cada persona capacitada" (Araya, Carrizo y López, 2006: 36). 
Aprovechando la infraestructura y el estado de avance de las tecnologías de información en el país, el Estado busca ampliar, estandarizar y nivelar a grandes sectores de la población -con relación a sus propias necesidades- en habilidades básicas de uso e integración de las TIC en sus funciones laborales y sociales regulares. Para ello, está desarrollando la Agenda de Alfabetización Digital, que pretende ampliar el beneficio de las nuevas tecnologías a la ciudadanía en general y asegurar calidad y relevancia en las competencias tecnológicas que desarrolla el país. Esto se traduce en que se busca lograr una mayor sofisticación, frecuencia y sentido en el uso de tecnologías por parte de los alumnos del sistema escolar público, los micro y pequeños empresarios y otros grupos sociales nacionales relevantes (adultos mayores, padres y apoderados del sistema escolar público, desempleados, entre otros), cada uno en atención a sus propias necesidades y características (Agenda Digital).

Al mismo tiempo, estas acciones de capacitación se refuerzan con una Campaña de Sensibilización Social -sobre la base de medios de comunicación locales y nacionales-focalizada a atraer a la sociedad en general hacia una mayor integración de TIC dentro de la cultura nacional.

\section{Procedimientos culturales de lectura}

Más allá del número de beneficiarios del programa y de su evidente aporte al desarrollo de las personas y del país, cabe llamar la atención sobre un aspecto muy relevante pero que puede pasar inadvertido. Se trata de la noción comunicacional que subyace en el diseño de este proyecto, pues se observa que, por definición, el concepto de "alfabetización" remite a la linealidad propia del texto escrito y de la lógica de la lectoescritura.

Debido a lo anterior, la UNESCO ha sostenido su preocupación por este tema, partiendo de la simple idea de dotar a la población más desprotegida desde un conjunto de habilidades, como son la lectura, escritura y cálculo, a un marco de alfabetizaciones diversificadas y plurales. "Que la alfabetización es plural significa que sus usos e interconexiones son múltiples dentro de una sociedad, de una 
comunidad y durante la vida de un individuo. Las personas adquieren, aprenden y usan la alfabetización con diferentes propósitos, en diferentes circunstancias, marcadas por la historia, la cultura, la religión, el lenguaje y las condiciones socioeconómicas. Procura enfatizar en que la alfabetización no es uniforme, sino cultural y lingüísticamente diversa, como se refleja y manifiesta en diferentes documentos, idiomas, y es utilizada en distintas prácticas sociales que cambian con el tiempo y con el lugar" (Aoyagi).

En el mismo sentido, las exigencias contextuales a los contenidos de la enseñanza formal imponen en la alfabetización nuevas categorías conceptuales, en las cuales "no pueden estar ausentes las nuevas tecnologías de la información y la comunicación, ya que actualmente la posibilidad de aprender está estrechamente vinculada a los formatos representacionales que ellas nos ofrecen. Pero el aprovechamiento pedagógico racional y efectivo de las nuevas tecnologías depende de un proyecto educativo que les otorgue sentido, atendiendo siempre a los valores y objetivos de la educación y al mejoramiento de la calidad de los procesos educativos" (Vázquez de Aprá).

Efectivamente, no todos los sujetos son capaces de integrar la lógica y las representaciones de mundo de la manera compleja que requiere el considerar como signo la tecnología. En efecto, "los sujetos participan segmentadamente en un uso funcional" (Valenzuela, 1996) de estos bienes, lo que resulta evidente al observar la aproximación en materia de ámbitos sensoriales de grupos etarios como los nacidos antes de la Segunda Guerra Mundial. De acuerdo con Piscitelli, ellos "aborrecen los medios masivos y en particular se han demostrado impotentes para desarrollar las destrezas multilaterales necesarias para vincularse al mundo a través de pistas y frecuencias diferentes y simultáneas, exigidas por las nuevas gramáticas audiovisuales y multimediáticas" (Piscitelli, 1998: 56).

Por el contrario, el autor señala que las generaciones de las décadas del 50 o del 60 y las siguientes son capaces de realizar automáticamente el ejercicio que requiere la lógica digital, a veces, con cierta dificultad. Esto ocurre, pues muchos de los sujetos aptos para integrar esta dinámica, "a pesar de ejercer, ya sea como producto o 
expectativa, un uso funcional de los nuevos artefactos tecnológicos, están lejos, en su mayoría, de poder efectuar una interpretación, un filtro hermenéutico adecuado sobre esos mismos objetos" (Valenzuela, 1996: 78).

Las generaciones más recientes presentan otro tipo de acercamiento a los artefactos, cuya repercusión social ha sido estudiada, entre otros, por Sherry Turkle en su libro "El Segundo yo". El estudio advirtió que si un grupo amplio de personas (hackers, computistas, fanáticos o simplemente usuarios) "usa tan frecuentemente las máquinas como para llegar a pensar como una o a considerar que la máquina es un buen modelo del pensamiento, entonces estamos frente a la emergencia de una nueva cultura" (Turkle, 1984: 93).

\section{Las edades tecnológicas}

Debido a las edades tecnológicas que les toca enfrentar desde los inicios de su vida social, los sujetos no perciben igual. Las operaciones cognitivas de quienes nacen en una cultura digital (nativos) son diferentes a los que se insertan a posteriori en ella (inmigrantes digitales), o de aquellos, como la tercera edad, que nacieron en una cultura lingüística, o los adultos de hoy que nacieron en una cultura audiovisual. Las edades no son sólo categorías biológicas, también "representan pertenencias distintivas y sucesivas constitutivas, en el hecho, de la identidad del sujeto en diferentes momentos de su existencia a la cual él se enfrenta" (Lamiset, 2004: 11).

Como consecuencia de lo anterior, los diversos formatos mediáticos exigen al individuo distintas herramientas de aproximación a los productos comunicacionales, lo cual da origen a la utilización de procedimientos de lectura cultural diferenciados para cada gramática de los medios. El sujeto realiza un acto de leer las construcciones mediáticas a partir de la gramática de dichos textos. Esta deconstrucción de los códigos de los productos mediáticos es lo que entendemos como procedimientos de lectura. Como tal, "los lectores desarrollan estrategias para tratar con el texto de tal manera de poder construir significado o comprenderlo" (Goodman, en Ferreiro y Gómez, 2000:21). 
En el caso de la televisión, la lectura cultural que efectúa la audiencia da cuenta de la naturaleza del medio. El sujeto deconstruye el texto mediático apoyándose en la estructura fragmentada que éste presenta. El teleespectador es capaz de generar y sostener diversos textos simultáneamente a partir de la información que, en forma dispersa, ha recogido de una sucesiva -y muchas veces discontinuainteracción con este medio de comunicación.

Así, la textualidad televisiva propicia el zapping como ejercicio de hiperlectura: "El sujeto se ve incentivado a realizar, a partir de un material disperso, una serie de reenvíos significantes. Esto quiere decir que el individuo debe apelar a sus propias construcciones previas, tanto en lo referente a contenido como a estructuras comunicacionales. De esta forma, tendrá la posibilidad de desarrollar estrategias para comprender la información fragmentaria que se le presenta, llevando a cabo exitosamente el desafío que enfrenta como lector, independiente del medio, articulando significativamente un texto" (Araya, Carrizo y López, 2006: 24).

Por otra parte, actúa a modo de respuesta a los formatos y productos mediáticos, impulsando al espectador a una continua reanudación de la lectura cultural que debe operar en este medio.

La televisión, entonces, generó un cambio en el entorno comunicativo. El comportamiento de la audiencia sufrió una modificación paulatina, pues con el tiempo los televidentes no sólo fueron absorbidos por la presencia de la imagen, sino que además aprendieron a convivir con la televisión. "La televisión (...) no es algo que se contempla. Se trata (...) de una máquina de contactar que está simplemente encendida todo el tiempo" (Piscitelli, 1998: 35).

La interacción con la televisión generó en los sujetos una cotidianeidad con el lenguaje audiovisual y sus códigos, entendidos como un sistema de signos y símbolos, determinados culturalmente, con los cuales el conocedor de los mismos puede comprender y emitir mensajes, y aprehendidos por los sujetos mediatizados en forma natural. 
Cada medio utiliza un tipo específico de variables de producción, algunas de ellas son transversales a diferentes medios: "Así, las variables propias de la fotografía fija y los medios sonoros funcionan también en la televisión y en el cine. Esto habla de competencias que contribuyen a la comprensión de códigos o formatos mediales basados en estructuras comunicativas preestablecidas. Esto es lo que sucede con la televisión y los nuevos medios, en particular internet. La red emplea una nueva codificación, a la vez que incorpora códigos de medios audiovisuales precedentes" (Araya, Carrizo y López, 2006: 35).

\section{Metodología}

Este estudio se define como una aproximación al problema y, por tanto, sólo intentó registrar y comparar las opiniones de estudiantes y profesores sobre el uso de las nuevas tecnologías en la actividad docente. Como se explicó anteriormente, la investigación se llevó a cabo en la Escuela de Periodismo de la Universidad de Santiago de Chile (USACH), unidad académica especializada en el dominio técnico de los nuevos medios.

En esta etapa inicial se descartó profundizar la observación o explicar en profundidad cómo los participantes -desde sus diversas competencias de lectura cultural-interactúan y se integran al fenómeno. Se optó por un método cuantitativo que validara los resultados de forma estadística, ordenando, sintetizando y permitiendo el acceso inmediato a los datos. Para tales efectos se utilizó una encuesta de carácter general, con el fin de sondear opiniones y no tratar cuestiones que exigieran una profunda reflexión de los entrevistados. Como el ideal del sistema de muestreo es trabajar con toda la población, se intentó realizar un censo que, por múltiples razones de funcionamiento de la entidad en la cual fue aplicado, no integró a la totalidad de sus integrantes, pero sí a porcentajes considerables: 246 de un total de 286 estudiantes regulares (86\%), y 33 de un total de 42 docentes (79\%).

En el dimensionamiento se consideró el uso y dominio de los nuevos medios por parte de los profesores, la utilidad atribuida y la valoración de ambos grupos. 


\section{Análisis de los resultados}

En los resultados de la encuesta aplicada a docentes y estudiantes de la Escuela de Periodismo de la USACH existe una gran coincidencia sobre el uso que dan los profesores a las nuevas tecnologías, lo cual hace innecesario presentar gráficos comparados. También se advierte una preocupación por el tema y mucho esfuerzo de actualización. Por ello, y para efectos de este trabajo, se ha seleccionado sólo una pequeña parte de los datos obtenidos, aquellos que permiten evidenciar que dicho esfuerzo consiste más en incorporar la mecánica de medios más sofisticados a las mismas metodologías de enseñanza, que adecuarse a otros formatos de interacción. En efecto, las actividades docentes se siguen basando principalmente en charlas frontales, en las cuales la mitad de los profesores sólo han sustituido la pizarra por un proyector de textos escritos, mientras un conjunto importante de recursos tecnológicos disponibles quedan sin uso, como se puede apreciar en los gráficos 1 y 2 :

\section{Gráfico 1}

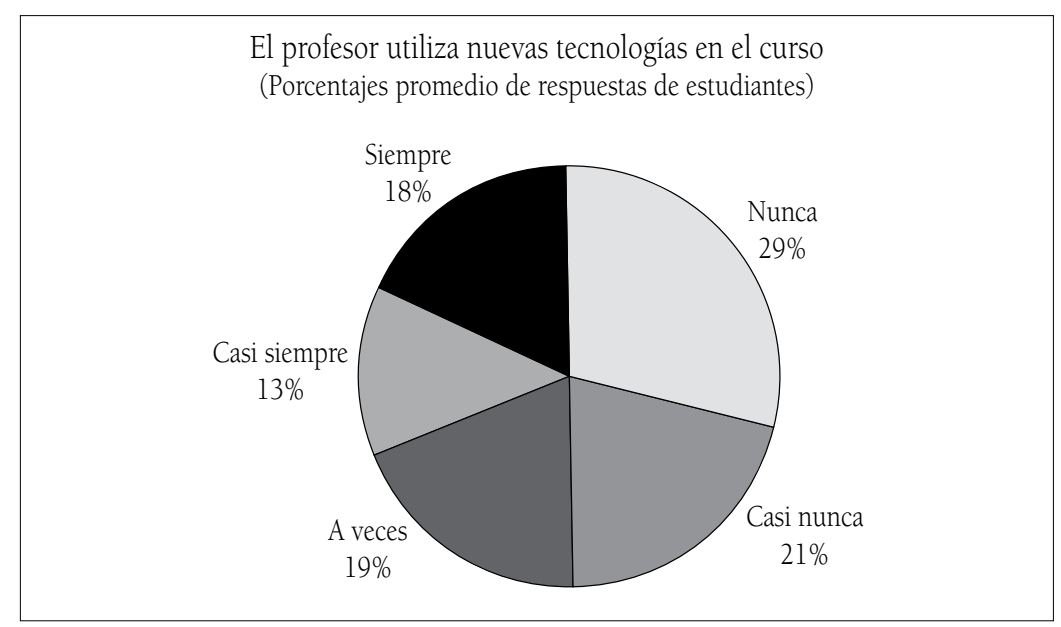


Gráfico 2

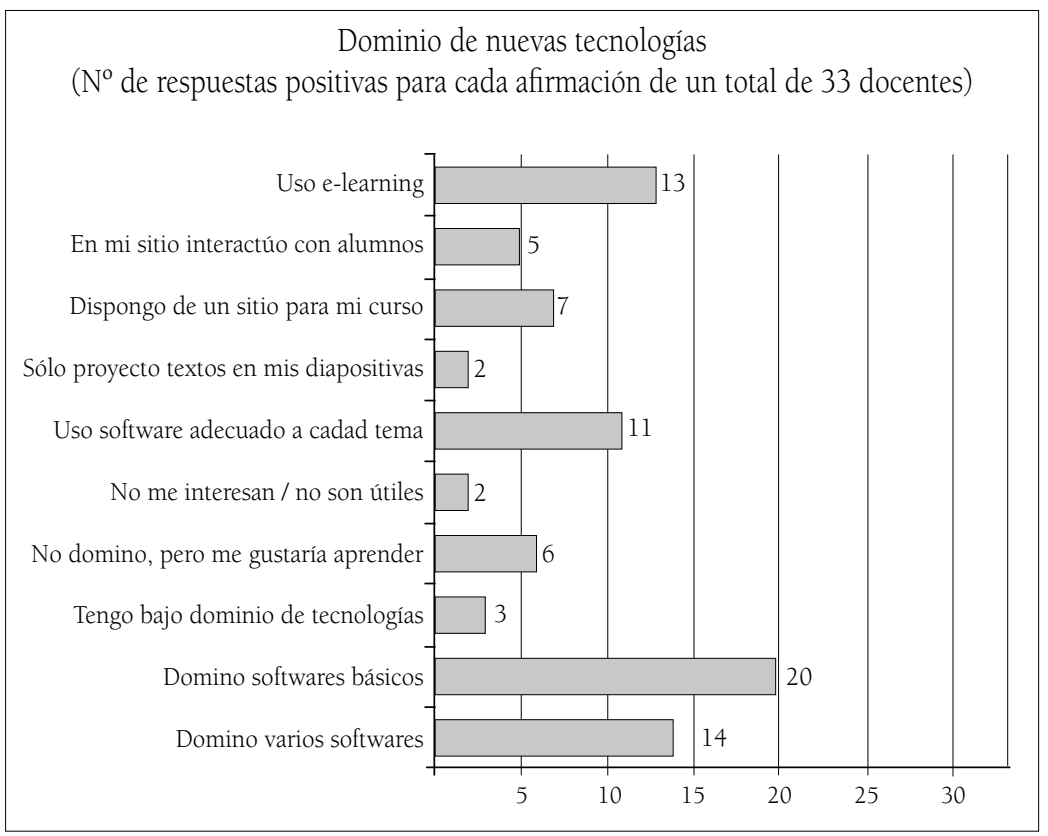

La actualización tecnológica de los docentes ha consistido principalmente en la integración de softwares básicos a sus labores, pero la navegación en códigos y formatos complejos, propios de las nuevas generaciones, siguen siendo extrañas a la labor pedagógica. Como se observa en los gráficos 3 y 4, la interacción por red con los estudiantes, que es la herramienta más poderosa de los nuevos medios, recién asoma como un recurso académico. Cabe señalar que las competencias de uso de la red se vinculan al dominio de códigos no secuenciales, como interactividad, multimedialidad, virtualidad, conectividad, entre otros, temas que forman parte del debate académico habitual en la Escuela de Periodismo de la USACH. 
Gráfico 3

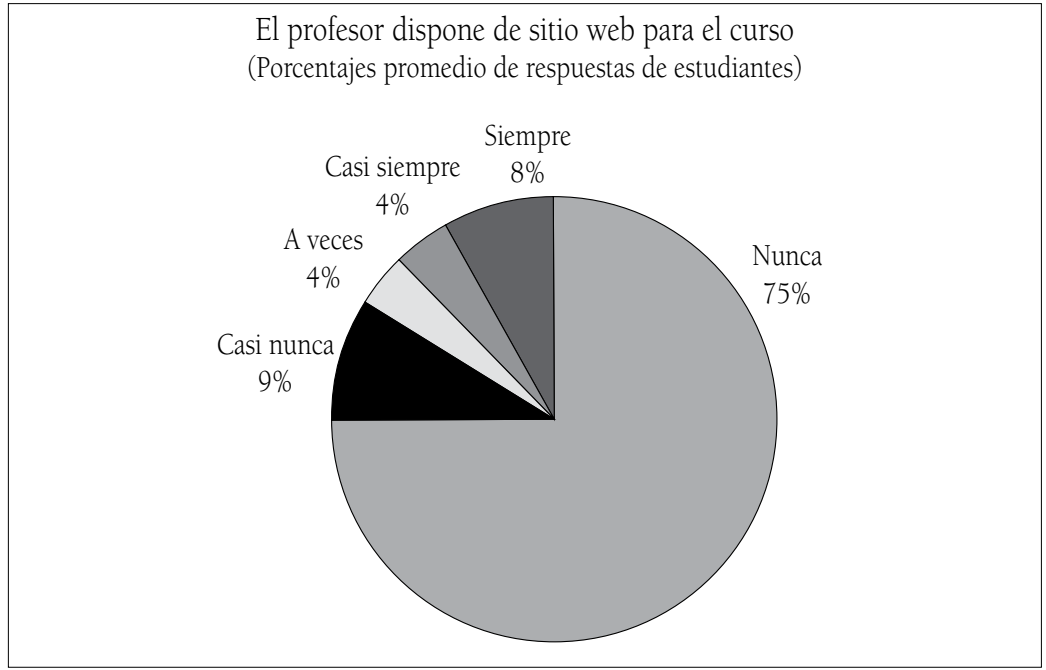

Gráfico 4

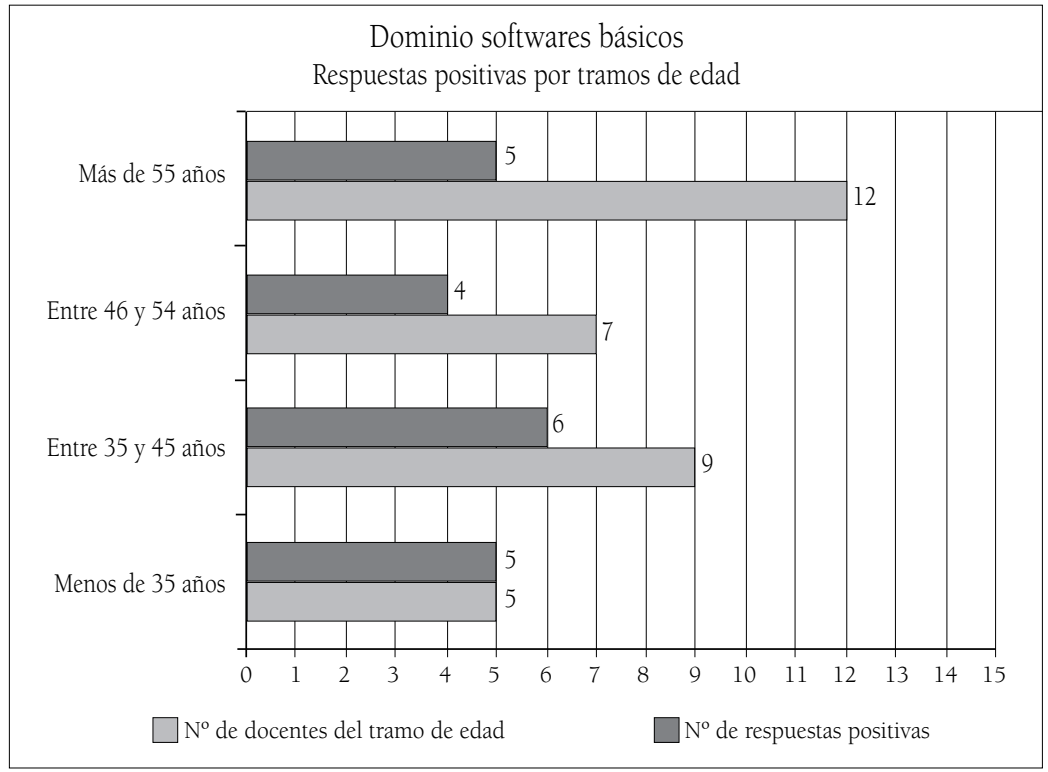

Finalmente, respecto de la distribución de apuntes, informaciones y textos varios, la fotocopia sigue siendo el soporte más recurrente, aunque el e-mail emerge como un medio utilizado en porcentaje similar. Lo anterior informa que la escritura es el código dominante en estas actividades, lo que se manifiesta en el gráfico 5: 
Gráfico 5

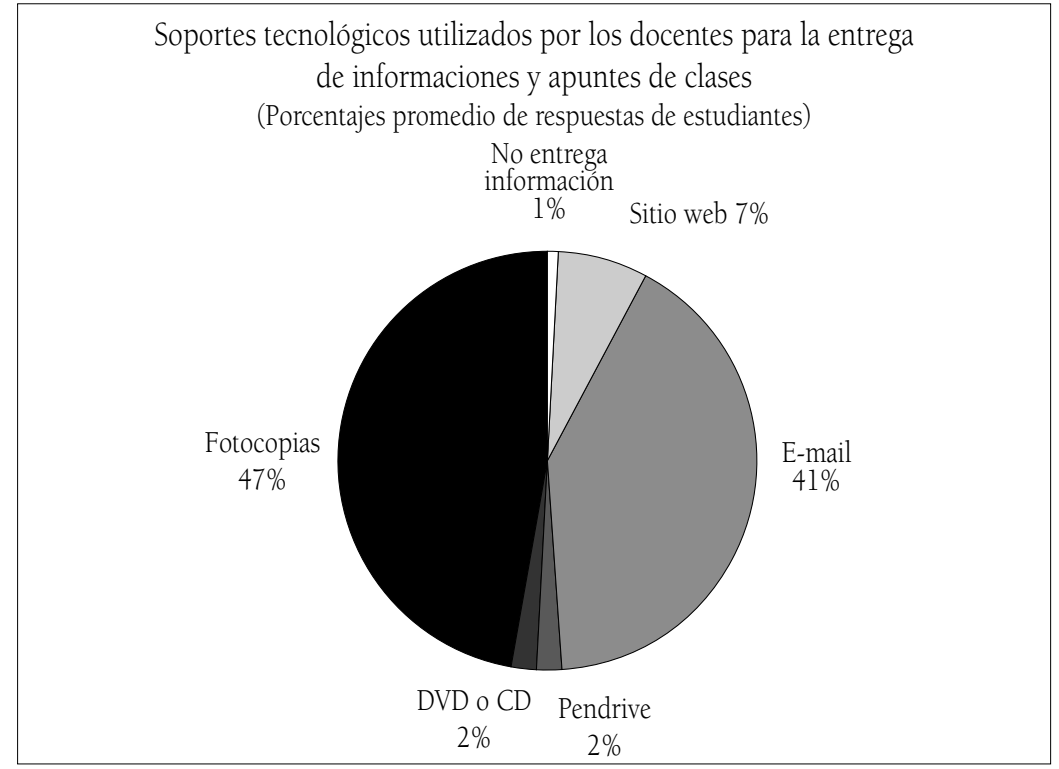

\section{Conclusiones}

De la observación de los datos obtenidos, respecto de la integración de nuevas tecnologías en la docencia universitaria, específicamente en una unidad académica especializada, es posible sostener que el fenómeno digital y sus procedimientos de lectura pueden ser abordados desde dos dimensiones. En primer lugar, tomando como referencia las características de producción que las nuevas tecnologías introducen en los medios de comunicación que se valen de ellas. Por otro lado, el fenómeno de los nuevos medios tiene lugar desde la relación intersubjetiva que se produce entre el usuario y el texto digital.

Precisamente, cuando se observan los gráficos de uso de nuevas tecnologías se puede apreciar que los docentes han incorporado una mínima parte de los recursos disponibles a sus clases y, generalmente, para sustituir formalmente otro medio, basado en códigos de la escritura tradicional. Lo más sorprendente es que esta opción no concuerda con los niveles de dominio de softwares ni con el manejo de otras posibilidades mediales o formatos emergentes. Se infiere, por lo tanto, que se trata más bien de un fenómeno paradigmático. 
Respecto del uso de internet, sistema que abre múltiples posibilidades complementarias al desarrollo de clases, apenas hay un atisbo de incorporación de sus códigos y formatos a la práctica pedagógica, como se aprecia en el gráfico descriptivo de la disponibilidad de sitios web para la docencia. En este caso, el fenómeno no es atribuible sólo al bajo dominio de las nuevas tecnologías que tienen los docentes, en proporción inversa a su edad, ya que las herramientas de red son manejables en el nivel de usuario básico, como mínimamente lo son los profesores de la unidad académica estudiada. El problema se explica porque las características del texto que afectan la lectura cultural de este medio se encuentran en la multimedialidad, la interactividad, la conectividad, la virtualidad y la hipertextualidad, derivadas de las nuevas tecnologías actualmente presentes en internet, lo cual, como soporte, "propicia lo multimedial, pues no hay impedimento material para que congenien texto, imagen y sonido" (Rodríguez de las Heras). Por lo tanto, la disolución de los límites entre lo verbal, los recursos sonoros y los aspectos visuales crea este nuevo producto textual que demanda un mayor compromiso por parte del usuario, debido a la complejidad que implica tener que coordinar los sentidos para percibir el texto como una unidad.

Además, porque está basada en la interactividad, la lectura en internet funciona sin un centro de atención permanente, ya que el usuario es quien determina el trayecto que seguirá en cada producto textual que enfrente. El eje central estará determinado por el sujeto "que se convierte así en un verdadero lector activo" (Landow, 1995: 24). Incluso, podemos especificar que el individuo pasa a tener un doble rol. Se convierte a su vez en lector y en autor de su propio texto, de acuerdo con los recorridos que él determine y elija. La interactividad está relacionada con el acceso voluntario a la información, es decir, "el usuario del hipertexto hace de sus intereses propios el eje organizador de su investigación del momento" (Landow, 1995: 24).

Finalmente, cuando se revisa el gráfico relativo a los soportes tecnológicos usados por los docentes para entregar información, se advierte que las lecturas lineales, propias de los códigos y formatos derivados de la escritura, son dominantes en los textos que se 
distribuyen entre los estudiantes, lo cual implica también que los contenidos de curso, las metodologías y las lógicas de acercamiento a los problemas tienen el mismo carácter.

En este contexto, una cuestión que no es posible obviar es "la necesidad de preparación de los docentes en el uso de las nuevas tecnologías para posibilitar su integración auténtica a la cultura escolar. Pero, lo que aún es más importante en los espacios de formación de maestros y profesores, sería conveniente pensar qué está ocurriendo actualmente en la realidad de las aulas y las escuelas. ¿Qué posibilidades de acceso, manejo y utilización de los medios tecnológicos tienen los sistemas escolares de sectores periféricos en donde se concentra la mayor parte de la población?" (Vázquez de Aprá).

Ahora bien, si en el uso de las nuevas tecnologías de comunicación concurren sujetos con distintas competencias en los procedimientos culturales de lectura, ¿mediante qué procesos se integran o al menos establecen campos de interacciones posibles? Probablemente, el terreno más adecuado para observar este fenómeno sea el educacional -particularmente, el universitario-, pues en él la capacidad "migratoria" no se reduce sólo a la "traducción" de textos producidos en diversos soportes sino a la comprensión metaobservada del fenómeno, que es el propósito de una unidad académica, como lo es la Escuela de Periodismo de la USACH.

La brecha de dominio tecnológico entre generadores y usuarios es tan amplia que puede ser medida en décadas. Por eso, la paradoja del atraso de una entidad especializada en la incorporación de los nuevos códigos y formatos invita a reflexionar sobre el contexto educativo nacional en el cual se desarrolla, pues sus actividades forman parte de una intrincada cadena de traspasos de tecnologías, en la cual se observan muchos esfuerzos en la distribución de equipamiento y pocos en la comprensión de su uso.

\section{Referencias bibliográficas}

Agenda Digital 2004-2006. Sitio en Internet. Disponible en http://www. agendadigital.cl 
Aoyagi, Shigeru, Jefe de la sección de Alfabetización y Educación no formal de la UNESCO. http://www.cesdonbosco.com.

Araya, Carrizo y López. (2006) Análisis de la presencia de las características metatextuales en diarios digitales chilenos. Valparaíso: Seminario de Título. Escuela de Periodismo de la Pontificia Universidad Católica de Valparaíso.

Calle, Aura M. (2000) El hipertexto: reivindicación de la lectura y la escritura en el medio electrónico, a un nivel más virtual que físico. Revista de Ciencias Humanas, Colombia. Sitio en Internet. Disponible en www. utp.edu.co.

Campaña Nacional de Alfabetización Digital, noviembre 2005.

Castells, Manuel. (1996) La Era de la Información: Economía, sociedad y cultura. Vol. I. México DF: La Sociedad Red.

Centro de Educación y Tecnología del Ministerio de Educación. (2005) Enlaces. Santiago de Chile: Ed. Enlaces.

Clèment, Jean. Del texto al hipertexto: hacia una Epistemología del Discurso Hipertextual. Sitio en Internet. Disponible en http://hipermedia.univparis8.fr

Colle, Raymond. (2002) Teoría Cognitiva Sistémica de la Comunicación. Hacia las raíces de la conciencia. Santiago de Chile: Editorial San Pablo.

Comunicación y Nuevas Tecnologías: la armonía es posible. Boletín Semanal Nº 70, noviembre de 1999.

Diviani, Ricardo. (1998) Conocimiento y nuevas tecnologías. Rosario: Universidad Nacional de Rosario. Argentina.

Ferreiro, E. y Gómez Palacio, M. (2000) Nuevas perspectivas sobre los procesos de lectura y escritura. México D.F.: Siglo XXI Editores.

Gómez-Martínez, José Luis. Hacia un nuevo Paradigma: el hipertexto como faceta sociocultural de la tecnología. Sitio en Internet. Disponible en http:// ensayo.rom.uga.edu

Lagos, Ricardo. (2000) Mensaje Presidencial, 21 de mayo 2000. Sitio en Internet. Disponible en http://www.camara.cl/hist/archivo/ discurs/21m2000.pdf

Lamiset, B. (2004) Les âges de la vie. Livre résumés Congrès de l'Association Française de Sémiotique: 11.

Landow, George. (1995) Hipertexto. Barcelona: Editorial Paidós.

Martín-Barbero, Jesús. (2006) Medios y culturas en el espacio latinoamericano. 
Pensar Iberoamérica, 5. Sitio en Internet. Disponible en http://www. oei.es/pensariberoamerica/ric05a01.htm.

Meneses, Javier. Códigos de interpretación en torno a la hipertextualidad. Venezuela, Universidad de Zulia. Sitio en Internet. Disponible en http://www.ucm.es.

Orrego C. y Araya R. (2002) Internet en Chile: Oportunidad para la participación ciudadana PNUD, 7, Temas de Desarrollo Sustentable. Sitio en Internet. Disponible en http://www.desarrollohumano.cl.

Park, Robert. (1972) Las Noticias como Forma de Conocimiento. En: Steinberg y Bluem. Los Medios de Comunicación Social. México: Editorial Roble.

Pisani, Francis. (2002) ¿Y ahora qué? En: Islas, O. y Gutiérrez, F. Explorando el ciberperiodismo iberoamericano. México: CECSA.

Piscitelli, Alejandro. (1998) Post/Televisión. Ecología de los medios en la era de Internet. Buenos Aires: Paidós.

Rodríguez de las Heras, Antonio. El Libro Digital. II Semana de Debate sobre l'ensenyament universitari de les Humanitats Tecnologies de la Informació i Humanitats. Sitio en Internet. Disponible en http:// www.uoc.edu

Trejo Delarbre, Raúl. (2001) Vivir en la Sociedad de la Información. Orden global y dimensiones locales en el universo digital. Revista Iberoamericana de Ciencia, Tecnología, Sociedad e Innovación, 1. Sitio en Internet. Disponible en http://www.campus oei.org/revistactsi/ numerol/trejo.htm\#la.

Turkle, Sherry. (1984) El segundo yo. Las computadoras y el espiritu humano. Buenos Aires: Galápagos.

Valenzuela Román, Yasna. (1996) Representaciones culturales de la relación Sujeto-Máquina. Santiago de Chile: Tesis para optar al grado de Licenciatura en Sicología, Universidad de Chile.

Vargas Gutiérrez, José Luis. (2002) Época de cambio o cambio de época. El debate actual, 4(2). Sitio en Internet. Disponible en www.saladeprensa.org

Vázquez de Aprá, Alicia. Alfabetización para el siglo XXI: nuevos significados, nuevos dilemas. Sitio en Internet. Disponible en http://www.unrc.edu.ar.

Recibido: 20 de diciembre de 2008

Aceptado: 27 de enero de 2009 